\title{
Soils and earthworms as a final chapter in the narrative of a steelworks
}

\author{
K.R. Butt \& S.M. Quigg \\ School of Forensic and Applied Sciences, University of Central Lancashire, Preston PR1 2HE \\ E-mail: krbutt@uclan.ac.uk
}

\section{ABSTRACT}

Hallside steelworks, South Lanarkshire, Scotland, employed thousands of people and constructed rails and ships for over a century, before this successful industry closed in the 1970s. The site, south-east of Glasgow, was then reclaimed from dereliction during the 1990s to produce biomass through Short Rotation Coppice (SRC) of willow trees (Salix spp.). On site, the contaminated soil was removed, and a rudimentary substrate created with a mixture of sewage sludge and colliery spoil, the latter moved from nearby tips to release land for housing. Trees were planted and earthworms (Annelida) added to potentially assist growth. Initially recognised as a flagship for reclamation, the site was then abandoned. In 2018, information was gathered on the development of soils and on earthworm communities. This was achieved by sampling across the 35 ha site below willow, other planted tree species and grassland. The results showed that reclaimed soils were very stony, compacted, resistant to water infiltration but relatively uncontaminated. Willow had grown, but coppicing had not occurred. Earthworm introduction was initially unsuccessful, but colonisation took place from adjacent unadulterated areas and 16 species from three ecological groups were recorded. Mean community density was $208 \pm 18.1$ earthworms $\mathrm{m}^{-2}$ with a mean mass of $71 \pm$ $6.1 \mathrm{~g} \mathrm{~m}^{-2}$. Type of vegetation cover had a significant $(P<0.05)$ effect on community density and biomass.
\end{abstract}

The site is now used for recreation and is an effective greenspace close to Glasgow.

\section{INTRODUCTION}

The site of the Hallside steelworks is $16 \mathrm{~km}$ south-east of Glasgow, close to the town of Cambuslang in South Lanarkshire, Scotland. Steel production took place there from 1873 until its closure in 1978. This steel supported war efforts and was used in the construction of railways, ships and the Forth Railway Bridge, with over 2,000 people employed on site during the Second World War (Borthwick, 1973). Fig. 1 shows an Ordnance Survey map of the site at its prime in 1934 (National Grid Reference: NS667602) and further images of the working site can be viewed online (Hampson, 2019). After over a century of steel production, buildings and structures were demolished during the early 1980s to leave the area derelict, covered with extensive concrete foundations, open basements and spoil heaps (locally referred to as bings) and contaminated with heavy metals (Borthwick, 1973; Richards et al., 1993; Scottish Greenbelt Company, 1996). For this reason, the site was regarded as a severe environmental problem due to the costs associated with "cleaning it up" through conventional reclamation methods, which would have involved the importation of good quality subsoil and topsoil.

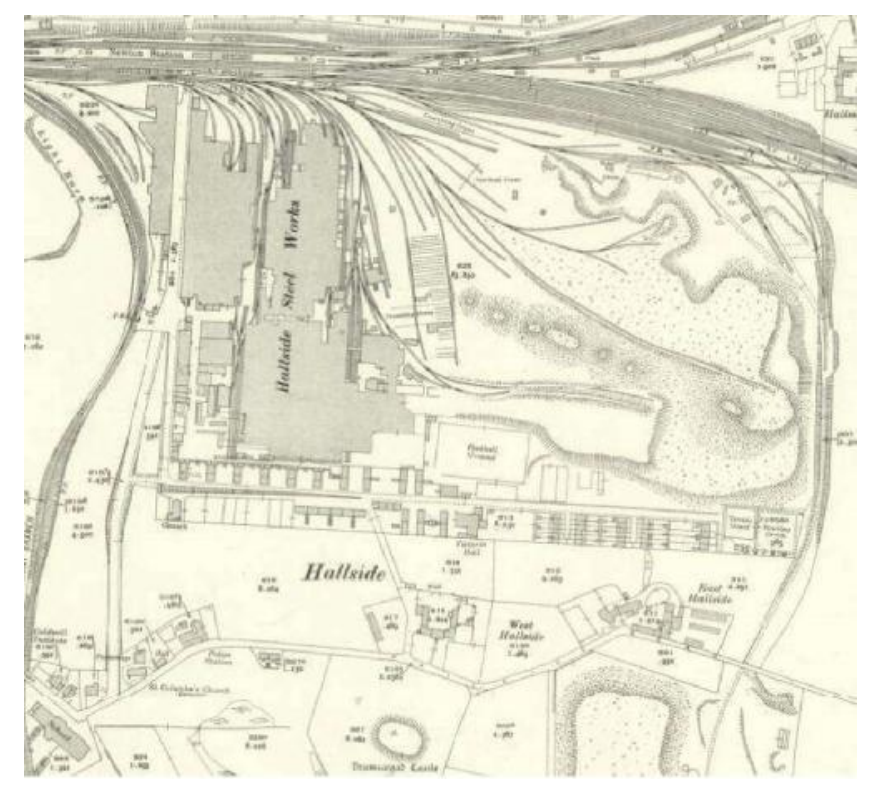

Fig. 1. OS map of Halls ide steelworks, Lanarkshire, Scotland from 1934 (available online from Borthwick, 1973). 
Development for housing or industry was therefore deemed unviable, so the site lay abandoned for over a decade. It was then acquired by the Strathclyde Greenbelt Company (later to become the Scottish Greenbelt Company), a charitable organisation whose main objective was to "sustain and enhance the landscape and ecological value of the Strathclyde Greenbelt" (Richards et al., 1993). With a need for new housing in the Clydesdale area during the early 1990s, development of greenbelt land was approved to the south of Hallside, with the agreement that this would be accompanied by the reclamation of the steelworks site to greenbelt use (by way of greenbelt mitigation). The proposed development sites were occupied by colliery spoil heaps which were cleared to make way for housing, which in turn financed the reclamation process (Richards et al., 1993; Scottish Greenbelt Company, 1996).

It was proposed that a large portion of the Hallside site would be used to create a "Renewable Energy Park", used for Short Rotation Coppice (SRC) of fast-growing tree species such as willow, which would provide wood for energy production. SRC harvest was proposed to occur every four to six years, following a staggered planting regime to ensure trees were available on an annual basis. A processing plant for the harvested wood was included in the development plans. The remainder of the site was to be planted as a broad-leaved community woodland to provide a screen between the energy forest and residential areas, to include pedestrian and cycle routes for recreational use (Richards et al., 1993). Organisations including the West of Scotland Water Authority, Scottish Enterprise, the Forestry Commission and Scottish Natural Heritage were initially involved in this project, as attested by a plaque (Fig. 2) that was ceremoniously unveiled on site by the Minister for Agriculture, Energy and the Environment in June 1996.

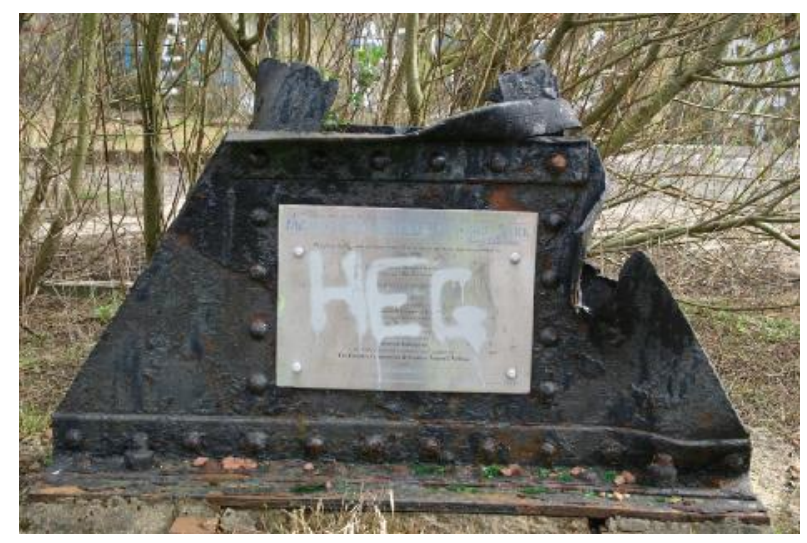

Fig. 2. Plaque to the "Hallside Renewable Energy Park" unveiled 1996, photographed 2005. (Photo: K.R. Butt)

After the removal of remaining concrete, metalwork and contaminated soil, a stone-rich material (colliery spoil) transported from nearby bings, as extracted and tipped decades before, was used to create a 1-2 m deep rudimentary "soil" at Hallside. To improve the soil for tree growth, 300 tonnes ha-1 of sewage sludge (bio- solids) was ploughed into the surface layers of the spoil to act as a fertiliser (Craven, 1995). Sewage was supplied from the local Daldowie sewage treatment works, which, until the European Union's Waste Water Directive came into effect in the 1990s, had previously disposed of sewage directly into the sea (Sutcliffe, 1997). It was hoped that the use of a high level organic fertiliser would accelerate the regeneration process and assist tree growth. To test this, pot trials had been established in 1992 using willow, poplar (Populus spp.) and red alder (Alnus rubra), to compare growth rates on colliery soil from Hallside with and without organic amendments (Craven, 1995). From these results, numerous species of willow were selected. Approximately 250,000 willow saplings were planted on the site in 1996, with a further 25,000 hardwood saplings planted to create an amenity hedgerow (Craven, 1995; Rees, 2010).

At the time of tree planting (1996) and to potentially assist tree growth and soil development, earthworms were added (inoculated) to the site through use of the Earthworm Inoculation Unit (EIU) technique (Butt et al., 1995) with $\mathrm{N}=2,000$ EIUs, each containing four adult Lumbricus terrestris, a deep burrowing (anecic) earthworm, and by depositing commercially supplied, earthworm-rich turf discs $(150 \mathrm{~mm}$ diameter; $30 \mathrm{~mm}$ depth). The latter contained a mixture of earthworms, dominated $(96 \%)$ by surface living (epigeic) species such as Dendrobaena veneta and Eisenia fetida (Butt, 2008). Previous trials (Craven, 1995) had suggested that anecic earthworms might successfully survive within the colliery spoil and sewage sludge mix and thereby effectively colonise the site. However, monitoring of the site over the two years after earthworm addition indicated that both inoculation techniques had been poorly implemented and few earthworms had persisted (Bain et al., 1999; Butt, 2008). The site was further monitored in 2000 (Mitchell, 2001) and it was found that by then earthworms had colonised the substrate and spread widely. An initial community $(\mathrm{N}=9$ species $)$ was dominated by the semi-aquatic, epigeic species Eiseniella tetraedra, with epigeics accounting for $95 \%$ of earthworms overall. Very few (2\%) endogeic (shallow burrowing) species were present and L. terrestris made up less than $1 \%$ of the community. The overall community density was 188 earthworms $\mathrm{m}^{-2}$. Further (small scale) monitoring took place in 2005 (Butt \& Lowe, 2005), nine years after the initial inoculation, when 12 earthworm species were found on site. These continued to be dominated by epigeics $(53 \%)$ of which Lumbricus rubellus and E. tetraedra were well represented. Aporrectodea caliginosa (the grey worm) was most frequent of the endogeic species which accounted for $38 \%$ of all earthworms.

After reclamation, few records of soil parameters were reported. One exception is from Mitchell (2001), whose earthworm-related M.Sc. project reported soil $\mathrm{pH}$ values of 5.5-7.5 from sampling points across the site. The site, which ought to have been coppiced on a regular basis over the period from the turn of the millennium, was largely neglected. The proposed processing plant was 
never built, although the willow grew well. The privately-owned Hallside Energy Park, never known to have produced commercial biomass, was fully abandoned in 2009, at which time responsibility was taken over by the Drumsagard Village Residents Association (DVRA) (Paterson, 2018). No further mention of the proposed Energy Plant for processing the willow has been found in the literature. The DVRA now manage the site for recreational use by the local community.

New investigations of the Hallside site took place in 2018 , with a specific focus on soils and earthworms. The specific aims were (1) to assess the extent of soil development in the 22 years since reclamation and (2) to examine the communities of earthworms that were present and relate these to inoculations and/or colonisation from adjacent areas.

\section{METHODS}

\section{Sampling points}

During spring 2018, investigations were undertaken within the reclaimed areas from the 1990s, with comparisons drawn from sampling in adjacent areas that were unadulterated. Fig. 3 shows an aerial view of the site and the 24 selected sampling points. Most of these were in the dominant vegetation (willow) but other treecovered areas were also targeted along with more open grassland.

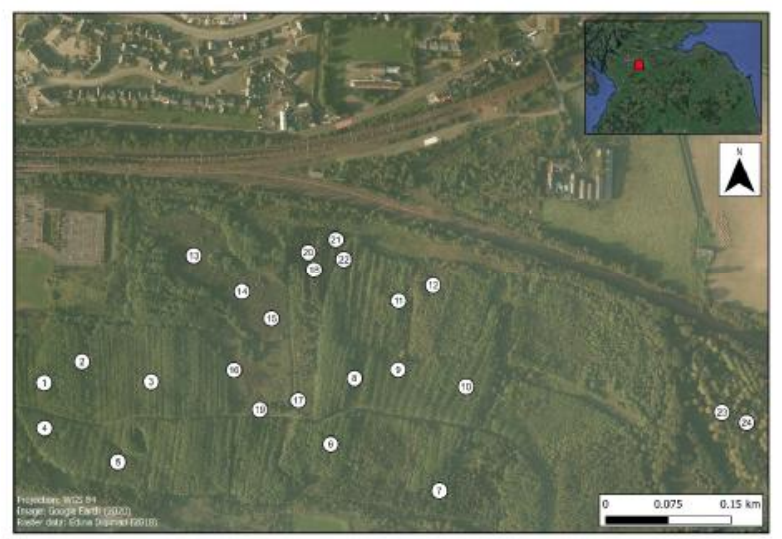

Fig. 3. Aerial view of the 35 ha reclaimed Hallside site, with position of the 2018 sampling sites indicated: 1-12, willow (Salix spp.); 13-17, grassland; 18-19, birch (Betula sp.); 20, Norway spruce (Picea abies); 21, Scots Pine (Pinus sylvestris); 22, cherry (Prunus sp.); 23-24, aspen (Populus tremula). Inset shows position of site in lowland Scotland (EDINA Digimap Service / Google Earth 2020).

\section{Soils}

Pits were dug, as deeply as possibly, in randomly chosen areas across the reclaimed site. This was to expose the soil profile and determine horizon development. At selected sites, under different vegetation cover, soil samples at $0-10 \mathrm{~cm}$, were collected from each point and placed in sealed polyethylene bags to prevent moisture loss. In the laboratory, these were analysed for percentage moisture content, $\mathrm{pH}$, percentage organic matter content - by loss on ignition (LOI) and by hand texturing (MAFF, 1981). Concentrations of heavy metals within soil samples were analysed using an Inductively Coupled Plasma Mass Spectrometer (ICP-MS) (Thermo Scientific X Series 1). Each soil sample was oven-dried at $80^{\circ} \mathrm{C}$ for $24 \mathrm{~h}$. Total $\mathrm{C}$ and $\mathrm{N}$ was determined using a C, N Elemental Analyser (Carlo Erba (THERMO), FLASH EA 1112 Series).

Penetration resistance was measured at the selected sampling point using a 06.01 Eijkelkamp penetrometer, which gave a single reading for each insertion. Water infiltration rate was also measured within selected habitats, using a plastic cylinder (void area $95 \mathrm{~cm}^{2}$ ) hammered into the soil and one litre of water added (adapted from Lassabatère et al., 2006). Infiltration rate was recorded or, if water remained after $5 \mathrm{~min}$, the remaining depth $(\mathrm{cm})$ was measured, with calculations to give infiltration rate $\left(1 \mathrm{~min}^{-1}\right)$. Three replicates of all measurements were taken per sample site.

\section{Earthworms}

The earthworms on site were sampled by digging a $0.1 \mathrm{~m}^{2}$ soil pit to $25 \mathrm{~cm}$ and hand-sorting the soil extracted on plastic sheeting in the field $(\mathrm{N}=3$ per location). In addition, to extract deep burrowing earthworms, an expellant of mustard powder and water $\left(5 \mathrm{~g} \mathrm{l}^{-1}\right)$ was applied to the base of the soil pit (Butt \& Grigoropoulou, 2010) (see Fig. 4). Earthworms were preserved in $4 \%$ formaldehyde for identification using the nomenclature of Sherlock (2018). In the laboratory, preserved masses were determined individually for species from each site and assigned to Bouché's (1972) ecological categories (epige, endoge or anecic). Statistical methods (ANOVA) were applied, as appropriate, to determine if the vegetation cover had an effect on the earthworm community density or biomass (per unit area). Willow sampling points were subdivided into either standard and "wet", based on observed standing water and tree height. In addition, ShannonWiener diversity index calculations were made, and comparisons drawn with previous (2000 and 2005) monitoring results from the site.

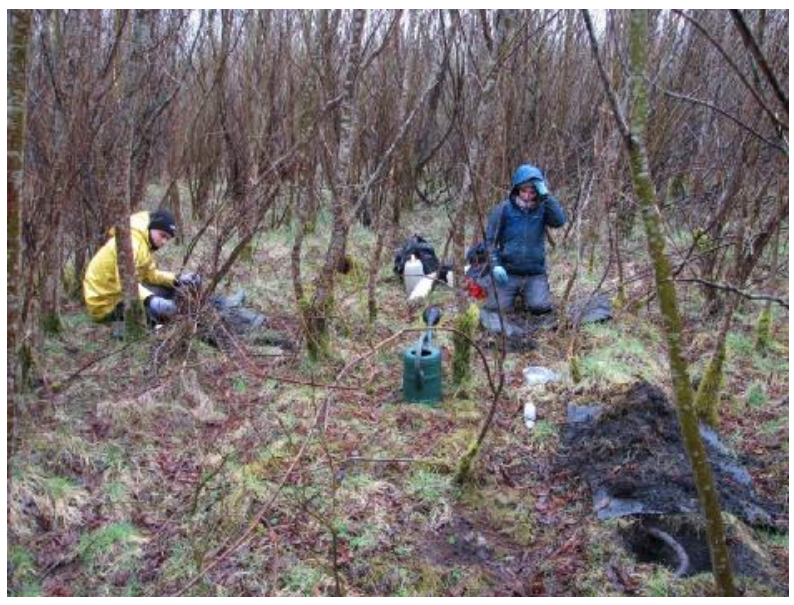

Fig. 4. Sampling for soil and for earthworms among willow at Hallside in 2018. (Photo: K.R. Butt) 


\section{RESULTS}

\section{Soils}

Soils in the reclaimed areas proved very difficult to dig as they had a high stone content. No pits could be dug further than a depth of $0.45 \mathrm{~m}$ and many digging attempts were hampered by large rocks. Fig. 5 shows that above the dark compacted, stone-laden horizon, there was a lighter less stony, organic A-horizon of some $0.15 \mathrm{~cm}$ from the soil surface. In control soils away from the reclamation site, major differences were observed (Fig. 5). Here, digging to $1 \mathrm{~m}$ was possible, with the upper $(0-35 \mathrm{~cm})$ organic layer determined as a grey, sandy clay loam above $35-100 \mathrm{~cm}$ of yellow sand. The upper layer held small fragments of colliery spoil as the area had previously been agricultural land and had been ploughed prior to alder planting.
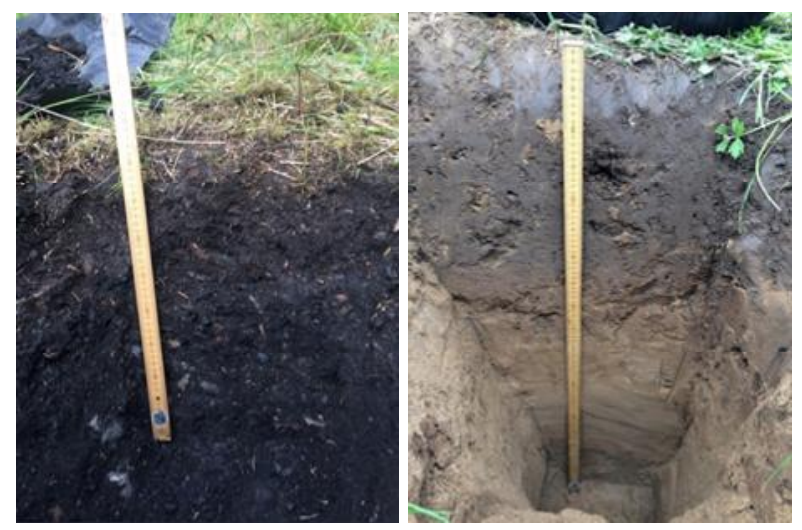

Fig. 5. Soil pits at Hallside. Left: in reclaimed soils below grassland (only possible to $45 \mathrm{~cm}$ due to stones and compaction). Right: in unadulterated sandy soil below aspen (to $1 \mathrm{~m}$ ). (Photo: K.R. Butt)

Table 1 shows results of selected physical and chemical properties (including heavy metals) from soil samples across site. The $\mathrm{pH}$ results are relatively consistent within a range of 1.5 units on the acidic side of neutral (5.1-6.6). These include slightly more acidic coniferinfluenced soils, although the sandy soil of the control area (below aspen (Populus tremula)) also had a $\mathrm{pH}$ close to 5. Values for LOI of 18-27\% obtained from the reclaimed areas were high compared with control soil value of $6 \%$. From nitrogen values within the reclaimed soils, C:N ratios of 3:1 to 10:1 were calculated. Sewage sludge will have initially promoted high nitrogen levels and accounted for growth of vegetation across site. Willow trees, originally intended to be coppiced after 4-6 years, reached heights of $12 \mathrm{~m}$ in some locations. However, where site drainage was poor, trees had survived, but with reduced growth. Soil moisture values ranged from $28-35 \%$ in reclaimed soils, compared with $25 \%$ in control areas. Infiltration of water varied across the site but was poor in places and mainly influenced by vegetation type. Some areas of the site had standing water at certain times of year but, were covered in terrestrial vegetation, further suggesting poorly-drained soils.

\section{Earthworms}

The investigations across site produced some 1,500 earthworms from 16 species (Table 2) equivalent to a mean $( \pm$ s.e. (standard error)) community density of 208 \pm 18.1 earthworms $\mathrm{m}^{-2}$ and a mean mass of $71 \pm 6.1 \mathrm{~g}$ $\mathrm{m}^{-2}$. Seven of these species were present in high numbers at the adjacent control site within natural soils. An additional two species were of those inoculated to the site using the turf discs in 1996. Two species (Murchieona muldali and Octolasion lacteum) were previously unrecorded from Hallside. Comparisons of different vegetation types showed a significant effect $(P<0.05)$ of habitat (differing dominant tree cover or grassland) on both earthworm community density and on biomass (Table 3). Fig. 6 shows the numbers of the different ecological categories of earthworms in these habitats. On the reclaimed site, significantly more earthworms were located where birch (Betula sp.) (height 12-15 m) was planted and where grassland had developed (community densities of 274 and 294 earthworms $\mathrm{m}^{-2}$ and biomasses of 104 and $75 \mathrm{~g} \mathrm{~m}^{-2}$ respectively: Table 3). These habitats compared favourably with natural (i.e. unpolluted and ploughed) control soils, planted with aspen, with 267 earthworms $\mathrm{m}^{-2}$, and a biomass of $114 \mathrm{~g} \mathrm{~m}^{-2}$. Overall, areas where willow was present (including good and poor growth) and those supporting two coniferous tree species (Norway spruce (Picea abies) and Scots pine (Pinus sylvestris)) had intermediate community densities of 153, 187 and 193 earthworms $\mathrm{m}^{-2}$, respectively. However, when sub-divided by soil conditions, the standard willow then showed earthworm densities similar to those of grassland, birch and aspen, with significantly less within "wet willow". Below conifers, a mat of needles covered the soil surface and was particularly dense below Norway spruce. Soil below cherry (Prunus sp.) supported the smallest recorded number of earthworms, with a mean of 83 earthworms $\mathrm{m}^{-2}$.

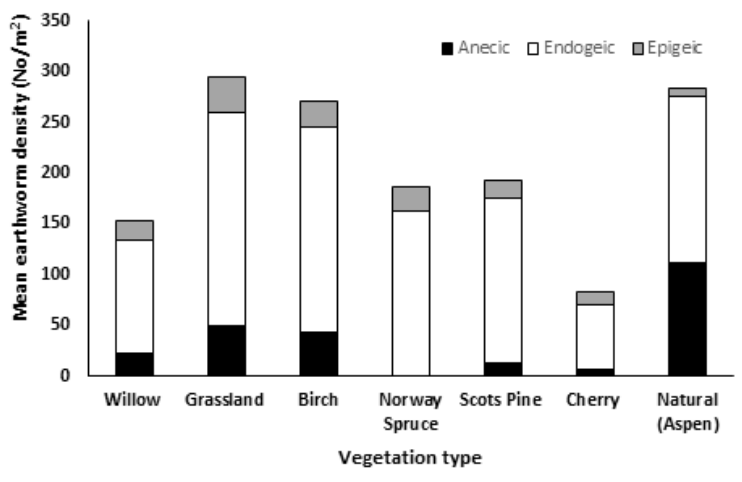

Fig. 6. Earthworm community data (by ecological category) at Hallside from below a variety of vegetation types on reclaimed soils and a more natural adjacent soil.

Overall, of the earthworms collected in 2018, endogeics accounted for $74 \%$ with A. caliginosa, Aporrectodea rosea, Octolasion cyaneum and Allolobophora chlorotica (green and pink morphs combined) equating to $34 \%, 27 \%, 8 \%$ and $5 \%$ respectively. The major anecic species was Aporrectodea longa (13\%). Epigeics accounted for only $5 \%$ of all earthworms and were dominated by Dendrobaena octaedra (4\%). 


\begin{tabular}{|c|c|c|c|c|c|c|c|c|c|c|c|c|}
\hline Soil Property & C:N & pH & $\begin{array}{c}\text { Moisture } \\
(\%)\end{array}$ & $\begin{array}{c}\text { Loss on } \\
\text { Ignition } \\
(\%)\end{array}$ & 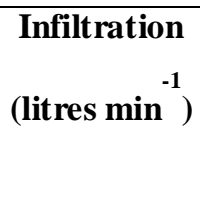 & $\begin{array}{c}\text { Penetration } \\
\text { Resistance } \\
\left(\mathrm{N} \mathrm{cm}{ }^{-2}\right)\end{array}$ & $\begin{array}{c}\mathbf{C r} \\
(\mathbf{p p m})\end{array}$ & $\begin{array}{c}\mathrm{Ni} \\
(\mathbf{p p m})\end{array}$ & $\begin{array}{c}\mathbf{C u} \\
(\mathbf{p p m})\end{array}$ & $\begin{array}{c}\mathbf{Z n} \\
(\mathbf{p p m})\end{array}$ & $\begin{array}{c}\text { Cd } \\
(\mathrm{ppm})\end{array}$ & $\mathbf{P b}$ (ppm) \\
\hline Willow & 9.55 & 6.13 & $31.7 \pm 2.0$ & $24.6 \pm 1.8$ & $0.90 \pm 0.26$ & $72.4 \pm 3.6$ & 102.38 & 83.25 & 166.27 & 1723.78 & 6.62 & 419.25 \\
\hline Grassland & 4.83 & 6.63 & $32.4 \pm 3.6$ & $27.3 \pm 6.9$ & $0.52 \pm 0.23$ & $72.1 \pm 4.7$ & 72.06 & 70.13 & 125.95 & 560.01 & 1.74 & 316.176 \\
\hline Birch & 8.71 & 6.12 & $32.3 \pm 2.0$ & $24.8 \pm 2.7$ & $0.32 \pm 0.12$ & $64.1 \pm 4.6$ & 67.61 & 58.69 & 45.54 & 473.97 & 0.61 & 109.22 \\
\hline Norway spruce & 2.99 & 5.13 & $28.5 \pm 0.9$ & $18.0 \pm 1.0$ & $1.20 \pm 0.13$ & $72.1 \pm 6.9$ & 62.52 & 57.29 & 47.34 & 122.57 & 0.64 & 80.83 \\
\hline Cherry & 3.90 & 5.83 & $34.7 \pm 0.6$ & $20.4 \pm 0.8$ & Not recorded & Not recorded & 68.84 & 77.97 & 73.79 & 247.24 & 0.93 & 152.5 \\
\hline Scots Pine & 5.80 & 5.43 & $33.2 \pm 3.0$ & $25.9 \pm 2.6$ & $0.32 \pm 0.03$ & $93.1 \pm 16.5$ & 65.60 & 63.25 & 70.58 & 439.77 & 1.57 & 172.38 \\
\hline Natural (Aspen) & 1.91 & 5.06 & $24.8 \pm 2.9$ & $6.1 \pm 1.0$ & $0.10 \pm 0.01$ & $62.1 \pm 2.0$ & 83.50 & 90.37 & 206.40 & 675.15 & 3.02 & 513.92 \\
\hline
\end{tabular}

Table 1. Selected mean ( \pm s.e.) physical and chemical soil properties at Hallside, Lanarkshire, Scotland (2018) (adapted from Butt \& Quigg, 2020). 


\begin{tabular}{|c|c|c|c|c|c|c|}
\hline Earthworm species & DAFOR (2018) & $\begin{array}{l}\text { Ecological } \\
\text { category }\end{array}$ & Inoculated (1996) & Present in 2000 & Present in 2005 & $\begin{array}{c}\text { In Natural area } \\
(2018)\end{array}$ \\
\hline $\begin{array}{l}\text { Allolobophora chlorotica (green } \\
\text { morph) }\end{array}$ & Occasional & En & $\mathrm{X}$ & $\mathrm{X}$ & $\mathrm{X}$ & \\
\hline $\begin{array}{l}\text { Allolobophora chlorotica (pink } \\
\text { morph) }\end{array}$ & Rare & En & & & $\mathrm{X}$ & \\
\hline Aporrectodea caliginosa & Dominant & En & & $\mathrm{X}$ & $\mathrm{X}$ & $\mathrm{X}$ \\
\hline Aporrectodea longa & Frequent & A & & $\mathrm{X}$ & $\mathrm{X}$ & $\mathrm{X}$ \\
\hline Aporrectodea nocturna & Rare & A & & & $\mathrm{X}$ & \\
\hline Aporrectodea rosea & Abundant & En & $\mathrm{X}$ & & $\mathrm{X}$ & $\mathrm{X}$ \\
\hline Dendrobaena octaedra & Occasional & Ep & & $\mathrm{X}$ & & \\
\hline Dendrodrilus rubidus & Rare & Ep & $\mathrm{X}$ & $\mathrm{X}$ & & \\
\hline Eiseniella tetraedra & Rare & Ep & & $\mathrm{X}$ & $\mathrm{X}$ & \\
\hline Lumbricus castaneus & Occasional & Ep & & $\mathrm{X}$ & $\mathrm{X}$ & $\mathrm{X}$ \\
\hline Lumbricus rubellus & Occasional & Ep & & $\mathrm{X}$ & $\mathrm{X}$ & $\mathrm{X}$ \\
\hline Lumbricus terrestris & Occasional & A & $\mathrm{X}$ & $\mathrm{X}$ & $\mathrm{X}$ & $\mathrm{X}$ \\
\hline Murchieona muldali & Rare & Ep & & & & \\
\hline Octolasion cyaneum & Frequent & En & & & $\mathrm{X}$ & $\mathrm{X}$ \\
\hline Octolasion lacteum & Rare & En & & & & \\
\hline Satchellius mammalis & Rare & Ep & & & $\mathrm{X}$ & \\
\hline
\end{tabular}

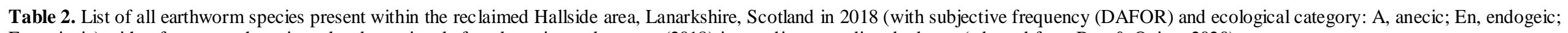
Ep, epigeic) with reference to those inoculated, previous ly found on site, and present (2018) in an adjacent undisturbed area (adapted from Butt \& Quigg, 2020). 


\begin{tabular}{|c|c|c|c|c|c|c|c|c|}
\hline \multirow[b]{2}{*}{ Earthworm data } & \multicolumn{7}{|c|}{ Vegetation Cover } & \multirow[b]{2}{*}{$\begin{array}{l}\text { Aspen } \\
\text { (Natural) }\end{array}$} \\
\hline & Willow & Wet willow & Grassland & Birch & Spruce & Pine & Cherry & \\
\hline Mean earthworm density & $244.4 \pm 23.0$ & $48.0 \pm 10.3$ & $294.0 \pm 48.8$ & $274.4 \pm 52.4$ & $186.7 \pm 43.7$ & $193.3 \pm 46.3$ & $83.3 \pm 6.7$ & $266.7 \pm 40.4$ \\
\hline (No. $m^{-2} \pm$ s.e.) & $\mathrm{a}$ & $\mathrm{b}$ & $\mathrm{a}$ & a & $\mathrm{ab}$ & $\mathrm{ab}$ & $\mathrm{b}$ & a \\
\hline \multirow[t]{3}{*}{ Dominant spp. by number (\%) } & A.cal (42) & A.cal (30) & A.ros (32) & A.ros (36) & O.cyan (61) & A.cal (58) & A.cal (38) & A.long (35) \\
\hline & A.ros (19) & D.oct (13) & A.cal(28) & A.cal (32) & A.cal (21) & A.ros (25) & A.ros (21) & A.cal (31) \\
\hline & O.cyan (10) & D.rub (12) & A.long (14) & A.long (15) & L.rub (9) & A.long (7) & A.chlor (17) & A.ros (26) \\
\hline Mean earthworm biomass & $86.1 \pm 10.8$ & $23.98 \pm 6.05$ & $75.3 \pm 11.9$ & $103.8 \pm 20.3$ & $62.0 \pm 14.3$ & $58.0 \pm 13.7$ & $22.2 \pm 10.4$ & $114.4 \pm 27.1$ \\
\hline (Mass $\mathrm{g} \mathrm{m}^{-2} \pm$ s.e.) & a & $\mathrm{b}$ & $\mathrm{a}$ & a & $a b$ & $\mathrm{ab}$ & $\mathrm{b}$ & a \\
\hline \multirow[t]{3}{*}{ Dominant spp. by mass (\%) } & A.cal (29) & A.cal (23) & A.long (40) & A.long (42) & O.cyan (71) & A.cal (57) & A.long (50) & A.long (62) \\
\hline & L.ter (19) & A.noct (18) & A.cal (23) & A.cal (22) & A.cal (16) & A.long (55) & A.cal (25) & A.cal (16) \\
\hline & O.cyan (19) & O.cyan (13) & L.ter (14) & A.ros (12) & L.rub (9) & A.ros (10) & A.ros (12) & A.ros (9) \\
\hline
\end{tabular}

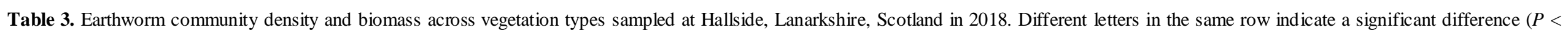

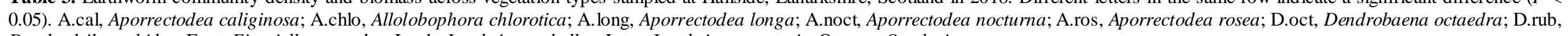

Dendrodrilus rubidus; E.tet, Eiseniella tetraedra; L.rub, Lumbricus rubellus; L.ter, Lumbricus terrestris; O.cyan, Octolasion cyaneum. 
The greatest proportion (39\%) of deep burrowing earthworms was located in the control soils adjacent to the reclaimed site. Comparisons below each type of vegetation can be seen in Table 3 .

Earthworm diversity across the site was characterised by a Shannon (H) Index of 1.89 with an evenness (measure of similarity between numbers of different species) of 0.68. Comparisons of previous monitoring at Hallside, for diversity, evenness and species richness, are also provided in Table 4.

\section{DISCUSSION}

\section{Soils}

In the reclaimed areas where soils were created, it appears that physical challenges, such as soil compaction, now outweigh any chemical problems for soil fauna that existed in the contaminated soils of the old steelworks. The current chemical nature of the reclaimed soils is such that soil fauna (specifically earthworms) can survive. Recorded levels of chromium and of cadmium fall within U.K. soil guideline values for residential use and allotments (DEFRA, 2018) (Table 1). Mean lead levels vary across site, but soil guide values are not available for this element. Most soil contaminants were removed from site before reclamation, but some metal contaminants must have been introduced with the spoil and sludge (Craven, 1995). The willow grown on site, in addition to providing a useful product, could also have assisted with decontamination of the site through uptake into the plants themselves (phytoremediation), although this was not given as one of the primary objectives at the time of reclamation. As willow biomass was not removed from site, this did not occur. High values for LOI could in part be attributed to the presence of combustible coal particles in the spoil, remnants of the sewage sludge and with more recent additions from the leaf litter of the given trees present. The acidic $\mathrm{pH}$ values were consistent with those reported by Mitchell (2001) from sampling nearly two decades earlier. Remnants of pyrites within the colliery spoil (Craven, 1995) may well keep these below neutral.

To overcome some of the physical challenges that still exist on site, greater thought could have been given to site preparation before tree planting. Although tree performance in most areas is acceptable on this type of land, sub-soiling may have alleviated the compaction problems, as recorded at restored colliery sites (Scullion \& Mohammed, 1991) and would certainly have prevented some of the problems associated with water pooling at the soil surface.

\section{Earthworms}

Historical data and current monitoring (Table 2) indicate that earthworm colonisation of the reclaimed site has occurred, with community density and biomass (208 $\mathrm{m}^{-2}$ and $71 \mathrm{~g} \mathrm{~m}^{-2}$ respectively) now equivalent to records from numerous U.K. pasture and woodland sites (Edwards \& Bohlen, 1996). The Hallside records are also equivalent to values $\left(203 \mathrm{~m}^{-2}\right.$ and $\left.56 \mathrm{~g} \mathrm{~m}^{-2}\right)$ obtained by Scullion \& Mohammed (1991) from rehabilitated (sub-soiled and fertilised) grassland on an opencast mining site, where soils may be considered similar.

Differences in earthworm community density and biomass that have developed below different stands of trees and on grassland can be attributed to the quality of the leaf litter produced. Willow, whilst supporting fewer earthworms, was planted to dominate this site for coppice production and the low lying (wet) soils seem to have favoured this tree species. However, where planted to gather data on growth rate and survival, other tree species (particularly birch) have survived. Future work could usefully investigate these directly for growth parameters and a range of associated soil macro-, mesoand micro-fauna.

As earthworm community density has increased, so has species richness at Hallside. This, however, is only something that can be learned from long term monitoring of a site. Investigations are usually shortterm, i.e. three to five years, but lengthier monitoring can prove to be invaluable, as not only do numbers change, but the proportions of the given species (community composition) can also be dynamic. Results for the major species recorded at Hallside have shown a steady increase in endogeics and a decrease in the epigeics, typified by E. tetraedra, which Mitchell (2001) reported as dominant, but which had decreased to become a minor component of the earthworm community by 2018 . As this species is semi-aquatic, its decrease may be attributed to changes in soil moisture dynamics on site and a decrease in the bio-solids content.

\begin{tabular}{|c|c|c|c|c|c|}
\hline $\begin{array}{c}\text { Monitoring } \\
\text { Year }\end{array}$ & $\begin{array}{l}\text { Years after } \\
\text { restoration }\end{array}$ & $\begin{array}{l}\text { Species richness } \\
\text { (S) }\end{array}$ & $\begin{array}{l}\text { Shannon-Wiener } \\
\text { Index }(\mathbf{H})\end{array}$ & Evenness (E) & $\begin{array}{l}\text { Major Species } \\
\text { across site }(\%)\end{array}$ \\
\hline 2000 & 4 & 9 & 1.01 & 0.46 & $\begin{array}{c}\text { E.tet (67); L.rub (18); } \\
\text { D.oct (9). }\end{array}$ \\
\hline 2005 & 9 & 12 & 2.16 & 0.87 & $\begin{array}{c}\text { A.cal (19); L.rub (19); } \\
\text { E.tet (18). }\end{array}$ \\
\hline 2018 & 22 & 16 & 1.89 & 0.68 & $\begin{array}{l}\text { A.cal (34); A.ros (27); } \\
\text { A.long (13). }\end{array}$ \\
\hline
\end{tabular}

Table 4: Species richness and diversity parameters of earthworms from Hallside, Lanarkshire, Scotland at post-restoration monitoring. Earthworm species abbreviations as for Table 3. 
Monitoring has shown that the soils at Hallside are compacted, have a high stone content and are resistant to water infiltration. The presence of deep burrowing earthworm species, such as L. terrestris, which create large burrows (diameter $7 \mathrm{~mm}$; depth $>1 \mathrm{~m}$ ) as a part of their everyday existence (e.g. Butt \& Grigoropoulou, 2010), would probably help and was one reason why this species was inoculated to site by managers in 1996. However, soils were too embryonic at that stage and incapable of offering support. Some 20 years on, an inoculation of this nature might still be inappropriate. Despite colonisation by some species, L. terrestris still struggles to produce deep burrows in these compacted, stone-rich soils and is forced to exist in shallow burrows, as previously recorded by Butt et al. (2014). A. longa, a smaller anecic species, is more suited to the soil conditions that have developed at Hallside as shown by its dominance of this ecological category. It may well have been a better candidate species for inoculation when the site was initially reclaimed.

\section{Conclusion}

From this investigation at Hallside, the given aims relating to reclaimed soils and earthworm community development have been addressed. These data may represent one of the final chapters in the narrative of this site. After more than two decades, reclamation at the Hallside steelworks site can be viewed mainly as a success. It has replaced a contaminated site and a large colliery waste heap, with a green space in an urban landscape. The site is now predominantly used by dog walkers and families for recreational purposes and a proposed development of the site has been made to create additional pathways within the woodland, to allow further access by members of the public. In addition, proposals to create new habitats and enhance existing habitats have been suggested, in order to increase biodiversity on site (Paterson, 2018). Rather than the plaque (Fig. 2) of the Renewable Energy Park that never was, a more fitting commemoration (Fig. 7) to the Hallside Steelworks is now present in the Park and Ride area of Newton Railway Station.

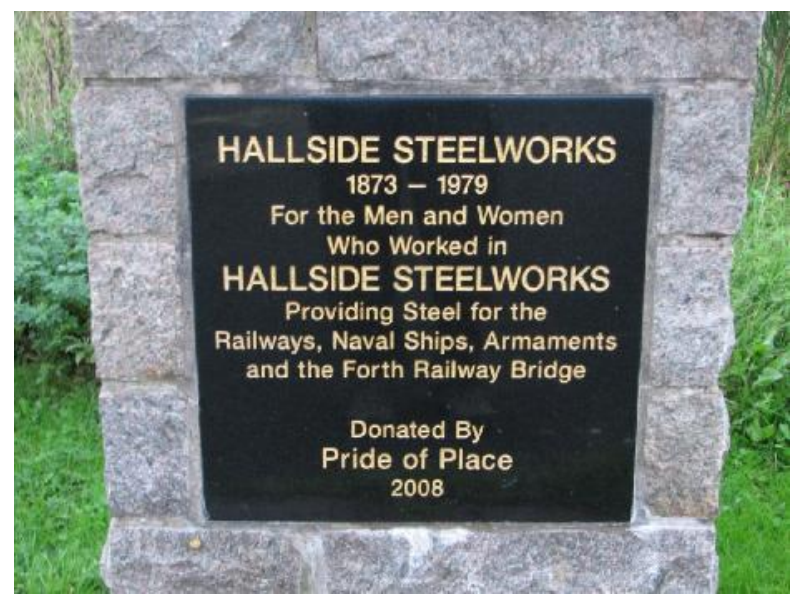

Fig. 7. Commemorative plaque to the Hallside Steelworks photographed in 2017. (Photo: K.R. Butt)

\section{Acknowledgements}

This work was supported by the British Land Reclamation Society Legacy Initiative [REF 3290]. The authors are grateful to Kevin Hoeffner for assistance with data collection at Hallside in spring 2018, Adam Peacock for production of Fig. 3 and to Colman's of Norwich, England for the supply of mustard powder.

\section{REFERENCES}

Bain, S.O., Butt, K.R. \& Morris, R.M. (1999). Survival and reproduction of Lumbricus terrestris in colliery spoil and sewage sludge. Pedobiologia 43, 729-734.

Borthwick, A. (1973). Hallside - One Hundred Years, 1873-1973. British Steel Corp. Special Steels Div. https://cfindlay17.wixsite.com/clydebridge/hallside1 Accessed 8th October 2018.

Bouché, M.B. (1972). Lombriciennes de France. Ecologie et Systématique. INRA, Paris, France.

Butt, K.R. (2008). Earthworms in soil restoration: lessons learned from UK case studies of land reclamation. Restoration Ecology 16, 637-641. https://doi.org/10.1111/j.1526-100X.2008.00483.x

Butt, K.R., Frederickson, J., \& Morris, R.M. (1995). An earthworm cultivation and soil-inoculation technique for land restoration. Ecological Engineering 4,1-9. https://doi.org/10.1016/0925-8574(93)E0053-S

Butt, K.R. \& Grigoropoulou, N. (2010). Basic research tools for earthworm ecology. Applied and Environmental Soil Science Article ID 562816. https://doi:10.1155/2010/562816.

Butt, K.R. \& Lowe, C.N. (2005). A Small-scale Investigation of the Earthworms at the Reclaimed Hallside Steelworks, Cambuslang, near Glasgow, Scotland. Report to Scottish Greenbelt Company. Ref: SGC05.

Butt, K.R., Lowe, C.N. \& Duncanson, P. (2014). Earthworms of an urban cemetery in Preston: general survey and burrowing of Lumbricus terrestris. Zeszyty Naukowe 17, 23-30.

Butt, K.R. \& Quigg, S.M. (2020). Earthworm community development in soils of a reclaimed steelworks. Pedosphere (in press).

Craven, D.R.J. (1995). The Hallside Steelworks Project. Land Contamination \& Reclamation 3(1), 31 - 38.

DEFRA (2018). Soil Guideline Values. https://www.claire.co.uk/information-centre/waterand-land-library-wall/44-risk-assessment/178-soilguideline-values Accessed 20th July 2018.

EDINA Digimap Service (2020). High Resolution $(25 \mathrm{~cm})$ Vertical Aerial Imagery [JPG geospatial data], Scale 1:500, Tiles: ns6659/6660/6759/6760, Updated: 29 October 2018, Getmapping, Using: EDINA Aerial Digimap Service, https://digimap.edina.ac.uk Downloaded 3rd March 2020.

Edwards, C.A. \& Bohlen, P.J. (1996). Biology and Ecology of Earthworms (3rd edition). Chapman and Hall, London.

Hampson, J. (2019). Hallside Steelworks - A Look at the Past.

https://www.bing.com/videos/search?q=hallside+yo utube $\&$ view=detail $\&$ mid=4F236A2BA5F13AE2F0 
Accessed 23rd October 2019.

Lassabatère, L., Angulo-Jaramillo, R., Soria Ugalde, J.M., Cuenca, R., Braud, I. \& Haverkamp, R. (2006). Beerkan estimation of soil transfer parameters through infiltration experiments - BEST. Soil Science Society of America Journal 70, 521-532. https://doi.org/10.2136/sssaj2005.0026

MAFF (1981). The Analysis of Agricultural Materials. A Manual of the Analytical Methods used by the Agricultural Development and Advisory Service $(A D A S)$ (2nd edition). HMSO, London.

Mitchell, A. (2001). The potential for Soil Inoculation with Earthworms to Restore Derelict Land to Forestry, within the Central Scotland Forest. M.Sc. Dissertation, University of Central Lancashire.

Paterson, J. (2018). Hallside Wood: Ecological Constraints and Opportunities Plan (ECOP) January 2018. Report by EnviroCentre Limited for TGP Landscape Architects.

Rees, S. (2010). The Potential for Utilising Disturbed and Contaminated Sites for the Production of Willow Short Rotation Coppice Forestry. M.Sc. thesis, University of Glasgow.

Richards, I.G., Palmer, J.P. \& Barratt, P.A. (1993). The Reclamation of Former Coal Mines and Steelworks. Studies in Environmental Science 56. Elsevier, London.

Scottish Greenbelt Company (1996). The Hallside Renewable Energy Park. Scottish Greenbelt Company, Glasgow.

Scullion, J. \& Mohammed, A.R.A. (1991). Effects of subsoiling and associated incorporation of fertilizer on soil rehabilitation after opencast mining for coal. Journal of Agricultural Science Cambridge 116, 265-273. https://doi.org/10.1017/S0021859600077674

Sherlock, E. (2018). Key to the Earthworms of the UK and Ireland. Field Studies Council, U.K.

Sutcliffe, A.D. (1997). From little seeds grow great ideas. The Herald 4th October. http://www.heraldscotland.com/news/12288460.Fro m_little_seeds_grow_great_ideas/ Accessed 9th July 2017. 